\title{
Encartes
}

ISSN 2594-2999, Bajo licencia Creative Commons

encartesantropologicos@ciesas.edu.mx

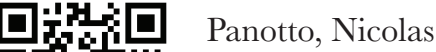

能楼

Lo evangélico como fuerza agonista: disputas hegemónicas frente a la transición política latinoamericana

Encartes, vol. 3, núm. 6, septiembre 2020-febrero 2021, pp. 36-51

Enlace: https://doi.org/10.29340/en.v3n6.180

Nicolas Panotto ORCID: 00000-0002-0513-7175

Disponible en https://encartesantropologicos.mx/ 


\section{COLOOUIOS INTERDISCIPLINARIOS}

LO EVANGÉLICO GOMO FUERZA AGONISTA:

DISPUTAS HEGEMÓNIGAS FRENTE A LA TRANSIGIÓN POLÍTIGA LATINOAMERIGANA

THE EVANGELICAL AS AN AGONISTIC FORGE: HEGEMONIC

DISPUTES IN THE FAGE OF LATIN AMERICAN POLITIGAL

TRANSITION

Resumen: El siguiente artículo procura reaccionar al estudio de Joanildo Burity titulado "El pueblo evangélico: construcción hegemónica, disputas minoritarias y reacción conservadora", el cual trata sobre la construcción de la "política evangélica" a partir de las nociones de "pueblo" y "lógica populista", desde el trabajo de Ernesto Laclau. El objetivo es destacar la relevancia de su aporte en la resignificación de algunas matrices de análisis sobre la identidad evangélica y su relación con el espacio público. Para ello, se complementará la propuesta de Burity con el uso de otras categorías dentro del propio andamiaje laclausiano, junto con los aportes de la producción desde el Cono Sur en torno al campo evangélico.

Palabras claves: campo evangélico, lógica populista, agonismo, identidad, política.

THE EVANGELICAL AS AN AGONISTIC FORGE: HEGEMONIC DISPUTES IN THE FAGE OF

\section{LATIN AMERICAN POLITIGAL TRANSITION}

Abstract: The following article attempts to react to the study by Joanildo Burity titled "The evangelical people: Hegemonic construction, minority disputes and conservative reaction", about the construction of "evangelical politics" from the notions of the "people" and "populist logic" from the works of Ernesto Laclau. The aim is to highlight the relevance of his contribution in re-signifying some analysis matrices on the evangelical identity and its relationship with public spac-

* Instituto de Estudios Internacionales-Universidad Arturo Prat.

ISSN 2594-2999, Bajo licencia Creative Commons

Encartes 6 • septiembre 2020-febrero 2020, pp. 36-51

Recepción: 14 de mayo de 2020 • Aceptación: 13 de agosto de 2020

http://www.encartesantropologicos.mx

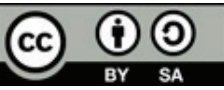


es. In order to do so, Burity's proposal will be complemented with the use of other categories within the same Laclausian framework, complementing with contributions from the production in the Southern Cone regarding the evangelical field.

Keywords: Evangelical field, populist logic, agonism, identity, politics.

T a creciente visibilización de grupos evangélicos en la esfera pública ha Simpulsado, como nunca se había visto, un fuerte interés por intentar comprender el fenómeno que representa el lugar que está cobrando este sector religioso dentro de las zigzagueantes dinámicas sociales latinoamericanas. Este reposicionamiento de lo evangélico en los nuevos escenarios del campo político regional ha puesto en tensión algunas visiones y conceptualizaciones instaladas en la materia, especialmente aquellas referidas a la laicidad, la secularización, el pluralismo religioso, entre otras. ¿Quiénes son "los evangélicos"? ¿De dónde provienen? ¿Cómo han alcanzado tal poder? Son preguntas que se repiten asiduamente y que evidencian no sólo el interés por discernir estas dinámicas, sino también los prejuicios, generalizaciones e inclusive la falta de precisiones a la hora de responderlas.

El texto de Joanildo Burity, "El pueblo evangélico: construcción hegemónica, disputas minoritarias y reacción conservadora", nos ayuda a analizar críticamente diversos acercamientos a la relación entre campo evangélico y política. Recurriendo al abordaje de Ernesto Laclau sobre la construcción de identidades sociales a partir del populismo como lógica política (Laclau, 2005), Burity despliega dos elementos significativos a destacar en torno a los modos en que se analiza el campo evangélico. Primero, que la identidad evangélica dista de ser un núcleo categórico con rasgos fijos; más bien inscribe la conjunción de una aglomeración de expresiones, narrativas, prácticas y determinaciones, muchas de ellas antagónicas. El autor precisa que la diversidad de memorias relacionadas con lo evangélico no debe ser interpretada sólo como emanaciones desde un "centro irradiador", sino más bien hay que comprender que "lo evangélico" encarna un significante constitutivamente abierto e internamente dividido. Es decir, la pluralidad evangélica no describe simplemente una diversidad estructural externa sino una caracterización constitutiva de lo propiamente evangélico en tanto identidad internamente fisurada. En términos laclausianos (Laclau, 2005: 64), el campo evangélico se construye desde una frontera interna que articula diversas cadenas equivalenciales que 
posibilitan desplazamientos internos constantes, y a su vez instituyen instancias de juntura con otros sujetos sociales.

Desde esto último, el segundo elemento importante que subraya $\mathrm{Bu}-$ rity es que no existe un telos (histórico o fenomenológico) en el actuar político evangélico, como lo puede mostrar una frase tal - de hecho muy divulgada- como "los evangélicos ingresan a la política". Este dictamen, en realidad, expresa no sólo una imagen homogeneizante de la movilización de este sector sino también una visión corporativista e institucionalista de su actuar político.

Burity presenta el concepto de minoritización (término que toma de Connolly, 2008) para dar cuenta de dos tipos de configuración que instituyen la acción política evangélica: una trama de modos de institucionalización (organizaciones, iglesias, agrupaciones, personas) y una lógica contra-hegemónica frente a otros sujetos o discursos que monopolizan (o pretenden hacerlo) tanto el ámbito social como el religioso. En otros términos, las matrices de movilización evangélica no son análogas, sino que responden más bien a dinámicas de articulación a partir de los diversos agentes y discursos que habitan y circulan en el campo. Los grupos evangélicos ingresan en el espacio público con el propósito de obtener reconocimiento y legitimidad como actores sociales, además de disputar hegemonía en torno a significantes como "el pueblo", "la nación", "la política", "la moral", entre otros.

Estos dos elementos de la propuesta de Burity se contraponen, como mencionamos, a algunos lugares comunes en los que caen ciertos análisis tanto académicos como periodísticos y políticos en torno al campo evangélico, a saber, la idea de una identidad religiosa homogénea (que ignora su amplísima diversificación interna) y un tipo de identificación política acotada a la incidencia en espacios de poder institucional, asociada a una ideología conservadora y de derecha (lo cual también deja de lado las múltiples prácticas y reapropiaciones políticas presentes, así como la tensión entre los bricolajes ideológicos que habitan en su seno).

Podemos decir que muchas de estas lecturas y propuestas analíticas ya estaban presentes, de manera incipiente o desde otros anclajes teóricos, en los estudios del campo evangélico en el Cono Sur desde sus orígenes. Recordemos, por ejemplo, la nominación de Matt Marostica (1994), quien a principios de los 90 denominó al campo evangélico como un nuevo movimiento social, argumentando que dicha expresión religiosa logró por enton- 
ces un fuerte afianzamiento en términos de "identidad cultural", es decir, como "espacio de expresión social". También lo vemos en los estudios de Hilario Wynarczyk (2009, 2010) con el concepto de campo de fuerzas, desde el cual identifica las tensiones y los conflictos dentro del sector evangélico, especialmente entre los dos polos que, según este autor, componen dicho grupo: el histórico liberacionista y el conservador bíblico. Wynarczyk también habla de grupos evangélicos como movimientos sociales cuya configuración identitaria se proyecta en el paso de ser un sector excluido dentro de esferas sociales y eclesiásticas monopólicas, hacia la creación de estrategias de acción y visibilización pública, reflejada en la conformación de partidos políticos y su participación dentro de debates públicos sobre temáticas socialmente sensibles, como lo fue la revisión del proyecto de libertad religiosa y el registro de cultos en Argentina (Wynarczyk, 2010).

De igual manera, encontramos una extensa bibliografía que demuestra con claridad que las prácticas políticas evangélicas son sumamente heterogéneas, donde se identifican y analizan las mutaciones que instituyen el puente entre lo religioso y lo público (Algranti, 2010; Carbonelli, 2008, 2009, 2011; Carbonelli y Mosqueira, 2010; Frigerio, 1994; Bahamondes y Alarcón, 2013; Burity, 2006, 2008a, 2008b, 201 1, 2015, 2016, 2017; Fediakova, 2013; Mansilla y Orellana, 2018; Míguez, 2000; Panotto, 2014, 2016a, 2016b; Parker, 2012; Semán, 2000, 2001, 2010, 2013; Wynarczyk, 2009, 2010, 2014, 2018). Esta producción desarrolla, entre otros aspectos, la diversidad territorial e institucional de los procesos de incidencia (sectores urbanos y populares; municipios, barrios y Estados), la pluralidad de grupos y clases sociales involucrados, los distintos tipos de agencia (cabildeo institucional, programas barriales, adscripción partidaria, incidencia desde organizaciones de sociedad civil, presencia en redes políticas), los diversos objetivos planteados (intervención en el tratamiento de políticas públicas, abordaje de temas como leyes de libertad religiosa, visibilización del lugar social de la iglesia), los distintos campos de acción, demanda y reacción (laicidad, derechos sexuales y reproductivos, pluralidad religiosa, estabilidad política y económica, derechos humanos) y las performances y militancias utilizadas (es decir, una incidencia que se traza desde lo institucionalista hacia una ética sociocultural). Todo esto, finalmente, se despliega desde expresiones ideológicas muy variadas que habitan y conviven en el mismo seno evangélico: conservadurismos, neoconservadurismos y progresismos, derechas e izquierdas, sumado a la extensa combinación entre 
todas ellas, y a la vez la existencia de muchas expresiones que se escapan de estas demarcaciones.

Si contrastamos este amplio espectro de estudios (que cubren un desarrollo de al menos cuatro décadas) con las imágenes, conceptualizaciones y nominaciones predominantemente estereotipadas que encontramos en análisis políticos y periodísticos actuales, nos preguntamos dónde reside ese hiato entre los existentes abordajes rigurosos y complejizados y las generalizaciones cimentadas en cierto "sentido común" circulante en algunos espacios. Como varios académicos han manifestado en recientes columnas de análisis (Seman y Viotti, 2019; Panotto, 2019; Mosqueira, 2019; Bahamondes, 2020), la falta de profundización respecto del análisis del campo evangélico no sólo promueve imprecisiones metodológicas sino también modos erróneos de abordar las dinámicas sociopolíticas, tanto de este grupo en particular como del mundo religioso en general.

De aquí, es importante enfocarse en dos preguntas relacionadas con dos ejes subyacentes en la propuesta de Burity que nos faciliten algunos insumos para abordar estas discrepancias epistémicas identificadas; a saber: el impacto de las disputas internas dentro del campo evangélico sobre los modos de analizar sus identificaciones políticas y los factores que entran en juego en las reapropiaciones de lo evangélico por parte del espacio público y los distintos agentes políticos. La primera sería: ¿cómo complejizar el análisis de la constitución identitaria del campo evangélico? En este asunto se juega algo que viene discutiéndose hace tiempo en el área de los estudios religiosos, y tiene que ver con la crítica sobre los modos estáticos de comprender las identidades creyentes a partir de una definición esencialista de la religión en tanto concepto sociológico, es decir, como una categoría con axiomas determinados y aplicable a todos los casos, pero más concretamente que inscribe identificaciones ontológicas inmóviles (Ceriani, 2013). En este sentido, "lo evangélico" también corre el peligro - como de hecho sucede reiteradamente con su uso $^{-}$de transformarse en una clasificación que homogeniza colectivos, reduce los tipos de vinculación y circulación entre agentes (internos y externos), y acota su acción sociopolítica en lugares comunes.

Esto nos trae al debate sobre la tensión entre los marcos de significación y los procesos de identificación, o lo que implica el uso de la categoría de identidad para los estudios religiosos ( $c f r$. Asad 1993: 27-54). Alejandro Frigerio (2007) habla de la importancia de diferenciar entre la identidad personal de los individuos, sus identidades sociales y la identidad colectiva propuesta 
por el grupo, como instancias entrecruzadas que no sólo determinan cómo el sujeto creyente se reapropia de lo religioso, sino, de hecho, cómo lo religioso (y todas sus irradiaciones en lo social, lo cultural y lo político) se transforma en una práctica circulante, antes que objetivada u objetivante. Como afirmaba Foucault (2003), no podemos hablar de sujetos en sí sino más bien de posiciones subjetivas que atraviesan nuestra identidad como un conjunto heterogéneo, y que se manifiestan como una trama que nos divide y a la vez nos ubica en distintos territorios, según las contingencias, los espacios, momentos históricos y prácticas dentro de nuestro locus sociocultural.

Lo mismo sucede con lo religioso: dicho universo puede ser asumido de múltiples maneras por cada sujeto (individual o colectivo) según contextos, momentos, procesos, contingencias. Por ello, en el plano evangélico (así como en toda identificación religiosa) tenemos que hablar de lo que Benjamín Arditi (2009: 38) denomina planos de identidad metaestables, es decir, superficies interpretativas maleables que son legitimadas a partir de cierta densidad histórica y discursiva adquirida en el transcurso temporal, y que se ponen en juego dentro de los procesos de identificación. Dichas superficies no simbolizan definiciones estáticas, sino que permiten la circulación de representaciones inclusive contrapuestas.

Dentro del campo evangélico podemos identificar al menos cinco superficies que entran en juego en este proceso, a saber: 1) las genealogías denominacionales (pentecostal, luterana, bautista, entre otras; sumando, además, las diversificaciones internas); 2) los contextos sociohistóricos y ambientales; 3) las corrientes teológicas (reformada, calvinista, liberacionista, anabautista y todas las posibles vertientes confesionales); 4) los posicionamientos político-ideológicos (conservador, neoconservador, progresista, evangélico crítico, entre otros); y 5) los procesos generacionales (enmarcados en las tensiones entre diversos grupos etarios y los conflictos institucionales por la adaptación sociohistórica). Todas estas superficies se entremezclan de maneras sumamente variadas, ya que es imposible hacer una correlación entre una genealogía denominacional y una corriente teológica, o un contexto sociohistórico y un posicionamiento sociopolítico. Pueden existir posicionamientos metaestables, pero desde tantos puntos nodales como sus posibles combinaciones. No es mi intención hacer una sistematización de estos ejes (que de hecho son mucho más complejos y variados) sino más bien resaltar que lo evangélico concierne a un marco 
identitario que, más allá de los lineamientos históricos que podamos encontrar (aunque, yendo a los inicios, la contraposición originaria entre Reforma Magisterial y Reforma Radical ya involucra de por sí un quiebre constitutivo), posee fronteras difusas, sumamente porosas y completamente flexibles.

A esto tenemos que agregar que cuando hablamos de sectores evangélicos incidiendo en el espacio público, no podemos hablar sin más de "la iglesia", como si dicha institucionalidad -de por sí ya sumamente ambigua y diversa- representara todos los modos de apropiación de la incidencia evangélica. En otro trabajo (Panotto, 2020) presento la existencia de distintas inscripciones institucionales que responden al espectro evangélico dentro del espacio público, representando cada una de ellas agentes y tipos de identificación política diversos. Por ejemplo, mientras que en los espacios eclesiales los agentes (sujetos creyentes) son sumamente diversos (según la configuración comunitaria) y los tipos de identificación son más fluidos, plurales y hasta antagónicos (ya que es imposible afirmar que una iglesia local responde a un único marco teológico y posición ideológica), en Organizaciones Basadas en la Fe (OBF) o lo que podríamos denominar como Redes Políticas Religiosas (es decir, organizaciones de alcance regional o redes de oBf e iglesias cuyo objetivo responde a una agenda de incidencia sobre políticas públicas nacionales o dentro de organismos multilaterales) nos encontramos con agentes mucho más homogéneos (no solo laicado o pastores sino creyentes profesionales en el campo de la incidencia política, muchos de ellos con militancias partidarias específicas) y agendas más concretas, acotadas e ideológicamente direccionadas.

Siguiendo otro término cardinal de la teoría laclausiana sobre la lógica populista (Laclau, 1996: 69-86), lo evangélico en tanto marco de identificación está lejos de ser una localización suturada que apuntala sujetos delimitados. Representa, más bien, un significante vacío, es decir, una nominación particular cuya potencia nominante se deposita no precisamente en demarcar caracterizaciones específicas sino en habilitar reapropiaciones flotantes en términos discursivos, prácticos y contextuales de lo más variados, en este caso, procesos de incidencia política, identificación con idearios sociales, relecturas a partir de diversos marcos ideológicos, entre otros.

La segunda pregunta - hablando, ahora, de los factores que entran en juego en las reapropiaciones de lo evangélico por parte del espacio público 
y distintos agentes políticos- es la siguiente: ¿por qué "lo evangélico" ha adquirido tanta relevancia en estas últimas décadas? En otros términos, ¿cuáles son los factores que han llevado a visibilizar con más fuerza las comunidades evangélicas en estos últimos veinte años, siendo que dicha expresión religiosa viene tomando un notorio empuje en términos demográficos desde hace ya varias décadas más? ¿Es sólo por causa de factores de transformación interna o extensión numérica, o existen otros componentes subyacentes en el contexto actual?

Para responder a esto podemos retomar otras dos categorías dentro del andamiaje laclausiano: la relación entre demanda y articulación. Según Laclau (2005: 158ss), las demandas son el epicentro de la construcción de un espacio político. Lo público no se origina en la simple confrontación de fuerzas particulares que compiten por una legitimidad identitaria (en el sentido de una "guerra de posiciones" antagónicas por el solo hecho de una contraposición ideológica), sino a partir de demandas, es decir, de puntos de insuficiencia o necesidades dentro del campo social más amplio, que convocan a las distintas voces y perspectivas que componen el espectro político con el objetivo de responder a ellas. Las demandas, además, no sólo encarnan necesidades concretas, sino que señalan carencias dentro de los marcos simbólicos hegemónicos para leer y afrontar la realidad. Las dislocaciones que se producen en el ámbito social a partir de estas demandas impulsan la necesidad de encontrar nuevas cadenas equivalenciales entre los sentidos y las prácticas establecidas, con el propósito de movilizar hacia nuevas cosmovisiones, prácticas y modos de institucionalización. Por ello, las demandas no conllevan un cambio absoluto del modo en que se comprende el espacio social y sus agentes, sino más bien movilizan desplazamientos que facilitan otras articulaciones simbólicas y materiales dentro del mismo espacio.

Volcando estos elementos dentro del tema que nos compete, nos preguntamos: ¿cuáles fueron, entonces, las demandas que surgieron en estos últimos años e impulsaron nuevos desplazamientos tanto hacia dentro del campo evangélico como desde los agentes y sujetos sociopolíticos en el espacio público, que indujeron a la construcción de nuevos tejidos con esta expresión religiosa? Burity plantea la hipótesis, en el caso brasileño, de que la construcción de la identidad pentecostal como "identidad general de los protestantes" respondió a un "efecto agonístico" en la coyuntura del surgimiento de nuevas subjetividades políticas en el proceso postdictadura, 
a parir de los años 80. Encontramos propuestas similares en otros países (Wynarczyk, 2009; Mansilla y Orellana, 2018).

Este fenómeno puede ser trasladado también a otros momentos históricos, especialmente a los procesos de transformación política regional que tuvieron lugar entre finales de los 90 y principios del 2000, especialmente en dos campos: la profundización en las reconfiguraciones del campo religioso (especialmente del monopolio de la Iglesia católica) y las mutaciones en las agendas políticas, con el surgimiento de nuevos gobiernos progresistas. Con respecto al primer elemento, la Iglesia católica, aunque no ha perdido su hegemonía política, sí se ha visto desafiada no sólo por el crecimiento evangélico sino también por la perdida de confianza social que enfrenta, debido tanto a sus crisis internas como también a las tensiones que se han gestado entre la intransigencia de la ortodoxia eclesial y las emergentes demandas sociales en términos de nuevos derechos y procesos de inclusión. La nueva "era Francisco" ha movido un poco este tablero, pero no ha podido cambiar el curso del desplazamiento (Renold y Frigerio, 2014)

En este contexto, el campo evangélico surge como nuevo "mediador de religación social", como menciona Burity, frente a un nuevo conjunto de demandas populares, donde podemos identificar: 1) la necesidad de un cambio en la comprensión de lo religioso y su lugar social, especialmente desde los crecientes procesos de hibridación, postsecularización y desinstitucionalización de lo religioso; 2) una reconfiguración de las dinámicas micropolíticas (o de "la política del día a día", como la denomina Esteban de Gori), que responde a la crisis de las cosmovisiones y prácticas políticas tradicionales de corte institucionalista, y donde lo evangélico responde de manera estratégica a partir de su configuración dinámica (Semán, 2010); y 3) una presencia y performance más efectiva de grupos evangélicos en sectores con fuertes demandas sociales.

El segundo elemento para destacar en este contexto de transformación es el impacto del surgimiento dentro del espacio público de nuevas subjetividades políticas, y los debates que ello trajo en torno a demandas y temáticas como el feminismo, la diversidad sexual, la libertad religiosa y el Estado laico, la educación sexual y los derechos sexuales y reproductivos, y con ello, el tratamiento de proyectos de ley en estas áreas, que fueron habilitados por los gobiernos en este periodo. Esto impulsó a que diversos grupos vinculados al campo evangélico se visibilizaran con más fuerza, en 
términos de lo que José Casanova (1994, 2012) denomina religión pública, respondiendo a tres características que el autor describe como: 1) movilización de grupos religiosos como movimientos sociales, 2) lobby institucional en los ámbitos local, estatal y federal, y 3) movilización electoral de sectores religiosos y la posible organización en torno a partidos políticos. Esto levantó un activismo enfocado en la moralización de la política (Carbonelli, 2008), tanto en lo relacionado con una agenda valórica que confronta con estas áreas sensibles, como en lo que se entiende como un problema constitutivo en el espectro político institucional, denominado comúnmente desde el significante de "corrupción".

Como afirma Burity (2016), las lógicas de minoritización del campo evangélico -reflejadas en estrategias de resistencia e involucramiento en la arena pública a partir de lógicas rizomáticas desde los vericuetos que posibilita la propia institucionalidad política-, hicieron que "lo evangélico" se transforme en un significante que articula no sólo una forma innovadora de experiencia religiosa ( $\mathrm{y}$ sus efectos en la vida social), sino también de nuevas militancias, maneras de reconfigurar imaginarios sociales (bajo la contraposición de la universalidad de lo moral frente al "relativismo dañino" que implica un posicionamiento ideológico) y de performances carismáticas de liderazgo, que hacen espejo, en buena medida, con los liderazgos políticos emergentes en la región de tipo carismático y personalista. Es así como podríamos decir, a modo de ejemplo y en línea con lo planteado por Burity, que el empoderamiento de los grupos evangélicos conservadores nace de los procesos de articulación gestados con las "nuevas derechas" (es decir, el conjunto de gobiernos que surge en los últimos diez años, como reacción a la crisis de los modelos progresistas que configuraron la política regional desde finales de los 90 hasta 2015), que se levantaron para oponerse a las agendas públicas desde organizaciones de derechos humanos y disputar hegemonía política, y que encontraron en el campo evangélico un reservorio simbólico para pugnar no sólo por proyectos y agendas, sino también por lógicas políticas.

La fuerza con la que se manifiesta el surgimiento de lo evangélico en la actualidad, entonces, deriva de su capacidad de atender a un conjunto de demandas sociales en un contexto de agonismo (Mouffe, 2014) manifiesto en las tensiones que despertó en la sociedad civil y la clase política el manejo de nuevas agendas sociales. En este sentido, hay que comprender que el tratamiento de estas agendas no necesariamente creó un movimien- 
to pendular en términos de posturas dentro de la sociedad, sino más bien un escenario de profundas tensiones, discrepancias y conflictos que ni siquiera los gobiernos de turno pudieron resolver. Por ello, diversos grupos evangélicos se levantaron como agentes de moralización, reestructuración social y posicionamiento político frente a los sectores adversarios, respondiendo a este vacío de sentido que se produjo en los modos simbólicos de enunciar y comprender las dinámicas políticas desde los discursos y agencias hegemónicos, tanto progresistas como conservadores.

De esta manera, dieron lugar a la creación de nuevos discursos, cosmovisiones desde lo sagrado, mecanismos de articulación, recursos humanos y estrategias de incidencia para un nuevo "interludio" gestado entre las agendas en tensión, que exige otros modos de actuar político (frente a la crisis de los imaginarios hegemónicos) y otros modos de vivir la fe (frente a la crisis de la ortodoxia católica y la emergencia de diversas expresiones religiosas). Además, los distintos sectores evangélicos sirvieron a la articulación con los sujetos políticos emergentes dentro del contexto de disputa hegemónica, según podemos ver en cada país, desde distintas coyunturas: en Brasil, vemos la llamada "bancada evangélica" por un lado, con una fuerte agenda conservadora, junto a los sectores monopólicos del país, y el Frente de Evangélicos pelo Estado de Dereito como una vertiente crítica y progresista; en Argentina, los gobiernos han priorizado con cuál federación evangélica acercarse según su agenda política: mientras los gobiernos kirchneristas se aproximaron más a la Federación Argentina de Iglesias Evangélicas (FAIE), que nuclea comunidades más abiertas con perspectivas inclusivas y desde los derechos humanos, el macrismo tuvo mayor relación con la Alianza Cristiana de Iglesias Evangélicas de la República Argentina (ACIERA), de corte más conservador; en Chile, el espectro de partidos políticos se vincula con grupos evangélicos por el rechazo o por la aprobación del proceso constitucional, según su agenda particular.

Para concluir, podríamos decir que en este período ya no es posible hablar solamente de formas reactivas de hacer política dentro del campo evangélico, como modos de disputar y oponerse al surgimiento de otras agendas políticas contrapuestas a las matrices morales históricas (Cfr. Vaggione, 2005). Más bien, debemos hablar de procesos mucho más complejos y profundos, donde ya no se demarca solamente una frontera antagónica sino se disputa la construcción de un nuevo ethos sociocultural y moral, relacionado, por ejemplo, con lo que Burity menciona en su artículo sobre la 
traducción de un proyecto nacional promovido por la Iglesia Universal del Reino de Dios en Brasil, propuesto más concretamente por su líder, Edir Macedo. De aquí la relevancia de hablar de una política agonista, es decir, de un marco que va más allá de la inscripción de antagonismos amigo-enemigo, sino más bien, como plantea Burity remitiendo a la idea de momento populista (Mouffe 2018: 23-39), de una lógica que evidencia la bifurcación hacia dentro mismo del espectro evangélico y sus posibles ramificaciones en términos de disputa hegemónica por demandas constitutivas de la sociedad: la nación, el pueblo, el orden social, la educación, la familia, entre tantos más.

Ello cuestiona la existencia de una vía unidireccional de la performance política evangélica. Existen múltiples voces y lineamientos, que a su vez habilitan una diversidad de modos de articulación política en el campo social, con un espectro sumamente amplio de sujetos, ideologías, coyunturas históricas y proyectos sociopolíticos. Aquí reside, entonces, la importancia de complejizar el abordaje de la configuración interna de lo evangélico, para entender que su relevancia política procede no de un accionar de contraataque en bloque frente a un conjunto determinado de discursos o agentes, sino de su capacidad de articulación, hibridez, fluidez y maleabilidad para viabilizar y catalizar, a partir del sentido polivalente que constituye "lo evangélico", distintas demandas, prácticas y construcciones identitarias contrapuestas.

\section{$\Delta$}

\section{Bibliografía}

Algranti, Joaquín (2010). Política y religión en los márgenes. Buenos Aires: Ciccus. Arditi, Benjamín (2009). La política en los bordes del liberalismo. Diferencia, populismo, revolución, emancipación. Barcelona: Gedisa.

Asad, Talal (1993). Genealogies of Religion. Londres: John Hopkins University Press.

Bahamondes, Luis (2020, 9 de marzo). "Ser evangélico no es ser de derecha: las complejidades de un credo usualmente desestimado por la izquierda", en CIPER. Recuperado de https://ciperchile. cl/2020/03/09/ser-evangelico-no-es-ser-de-derecha-las-complejidades-de-un-credo-usualmente-desestimado-por-la-izquierda/, consultado 13 de mayo de 2020. 
Bahamondes, Luis y Nelson Marín Alarcón (2013). "Neopentecostalismos en Chile: transformación y resignificación del pentecostalismo criollo", en Luis Bahamondes (ed.), Transformaciones y alternativas religiosas en América Latina. Santiago de Chile: cisoc, pp.175-919.

Burity, J. A. (2006) "Cultura e identidad nas políticas de inclusao social", en Aécio Amaral, Jr. y Joanildo Burity (org.), Inclusao social, identidades e diferença. Sao Paulo: Annablume.

- (2008a) "Religião, política e cultura", Tempo Social, vol. 20, núm. 2, pp. 83-113.

- (2008b) "Cultura, identidades e inclusao social: o lugar da religiao para seus atores e interlocutores", Debates do Ner, vol .2, núm.14, pp. 23-43.

- (2011). Fé na revoluçao. Protestantismo e o discurso revolucionario brasileiro. Sao Paulo: Novos diálogos.

- (2015). "A cena da religião. Contingência, dispersão e dinâmica relacional”, Novos Estudos, núm. 102, pp.89-105.

(2016). "Minoritization and Pluralization. What is the "People" that Pentecostal Politicization is Building?", Latin American Perspectives. vol. 43, núm. 3, pp.116-132. https://doi.or$\mathrm{g} / 10.1177 / 0094582 X 16639238$

(2017). "Autoridad y lo común en procesos de minoritización. El pentecostalismo brasileño", Revista Latinoamericana de Investigación Crítica, vol. 6, núm. 6, pp.99-125.

Casanova, José (1994) Public Religions in the Modern World. Chicago: The University of Chicago Press. https://doi.org/10.7208/chicago/9780226190204.001.0001

- (2012). Genealogías de la secularización. Madrid: Anthropos.

Carbonelli, Marcos (2008). "Evangélicos y política en Argentina: entre la institucionalización y la autonomía", Mitológicas, vol. 23, pp. 47-65. (2009). "Desde el barrio: perspectivas acerca de la actividad política de pastores evangélicos en el conurbano bonaerense", Ciencias Sociales y Religión, vol. 11, núm 11, pp. 107-129. https://doi. org/10.22456/1982-2650.8368

- (2011). "Ciencias Sociales, evangélicos y política. Una lectura sobre la producción científica acerca de la participación política evangélica en la vida democrática argentina (1983-2010)", Revista Cultura y Religión, vol. 5, núm. 2, pp. 96-116. 
Carbonelli, Marcos y Mariela Mosqueira (2010). "Militantes del Señor: cosmología y praxis evangélica sobre el espacio público", Sociedady religión, vol. 20, núm. 32-33, pp.108-123.

Ceriani, Cesar (2013). "La religión como categoría social: encrucijadas semánticas y pragmáticas", Cultura y Religión, vol. 7, núm. 1, pp.10-26.

Connolly, William (2008). Capitalism and Christianity, American Style. Durham: Duke University Press.

Fediakova, Evguenia (2013). Evangélicos, política y sociedad en Chile: dejando "el refugio de las masas". 1990-2010. Santiago: CEEP, IDEA / Universidad de Santiago.

Frigerio, Alejandro (1994). "Estudios recientes sobre el pentecostalismo en el Cono Sur: problemas y perspectivas", en Alejandro Frigerio (ed.), El Pentecostalismo en Argentina. Buenos Aires: Centro Editor de América Latina, Biblioteca Política Argentina, pp. 10-28.

- (2007). "Repensando el monopolio religioso del catolicismo en la Argentina", en Julia Carozzi y Cesar Ceriani (ed.), Ciencias sociales y religión en América Latina. Buenos Aires: Biblos, pp. 87-116.

Foucault, Michel (2003). Tecnologías del yo. Madrid: Editora Nacional.

Laclau, Ernesto (1996). Emancipación y diferencia. Buenos Aires: Ariel. (2005). La razón populista. Buenos Aires: FCE.

Mansilla, Miguel y Luis Orellana (2018). Evangélicos y política en Chile 19601990. Santiago: UNAP-RILL.

Marostica, Matt (1994). "La Iglesia Evangélica en la Argentina como nuevo movimiento social”, Sociedady Religión, vol. 10, núm. 12 , pp. 3-21 Míguez, Daniel (2000). "Modernidad, posmodernidad y la transformación de la religiosidad de los sectores medios y bajos en América Latina”, Revista Ciencias Sociales, núm. 10, pp. 56-68.

Mosqueira, Mariela (2019, 16 de noviembre) "Exorcizar el imaginario anti-evangélico", en Grupo de Estudios Multidisciplinarios sobre Religión e Incidencia Pública (GEMRIP). Recuperado de http://www.gemrip.org/exorcizar-el-imaginario-anti-evangelico/, consultado el 13 de mayo de 2020. Mouffe, Chantal (2014). Agonística. Pensar el mundo políticamente. Buenos Aires: FCE.

- (2018) Por un populismo de izquierda. Buenos Aires: Siglo XxI.

Panotto, Nicolás (2014). "Pentecostalismos y construcción de identidades sociopolíticas", Desafíos, vol. 26, núm. 2, pp. 73-96. https://doi. org/10.12804/desafios26.02.2014.03 
- (2016a). "Rostros de lo divino y construcción del ethos sociopolítico: relación entre teología y antropología en el estudio del campo religioso. El caso del pentecostalismo en Argentina", Debates do Ner, vol. 2, núm. 28, pp. 69-97. https://doi.org/10.22456/1982-8136.61268 (2016b) "Fe que hace la diferencia: prácticas religiosas, ontología(s) y construcción de lo público. Un caso dentro del pentecostalismo argentino", Liminales. Escritos sobre psicología y sociedad, vol. 1, núm. 10, pp. $29-45$

(2019, 15 de noviembre) "De evangélicos, generalizaciones y teorías de la conspiración", en Grupo de Estudios Multidisciplinarios sobre Religión e Incidencia Pública (GEMRIP). Recuperado de http://www.gemrip. org/de-evangelicos-generalizaciones-y-teorias-de-la-conspiracion/, consultado el 13 de mayo de 2020.

(2020). "Incidencia religiosa en clave multilateral: la presencia de redes políticas evangélicas en las asambleas de la OEA", Revista Cultura y Religión, vol.14, núm.1, pp. 100-120.

Parker, Christian (2012). "Religión, cultura y política en América Latina: nuevos enfoques", en Christian Parker (ed.), Religión, política y cultura en América Latina: nuevas miradas. Santiago de Chile: Universidad de Santiago de Chile, pp. 13-73.

Renold, Juan Mauricio y Alejandro Frigerio (comp.) (2014). Visiones del Papa Francisco desde las Ciencias Sociales. Rosario: unR Editora.

Semán, Pablo (2000). "El pentecostalismo y la religiosidad de los sectores populares", en Maristella Svampa (ed.), Desde abajo: La transformación de las identidades sociales. Buenos Aires: Biblos, 155-180.

- (2001). "La recepción popular de la teología de la prosperidad", Scripta Ethnologica, vol. 23, pp.145-162.

- (2010). "De a poco mucho: las pequeñas iglesias pentecostales y el crecimiento pentecostal. Conclusiones de un estudio de caso", Revista Cultura y Religión, vol. 4, núm.1, pp.16-35.

- (2013). "Pentecostalismo, política, elecciones y poder social", Sociedady Religión, vol. 7, núm. 1, pp.60-81.

Semán, Pablo y Viotti, Nicolás (2019). "Todo lo que usted quiere saber de los evangélicos le contaron mal", Revista Anfibia. Recuperado de http:/ / revistaanfibia.com/ensayo/todo-lo-que-quiere-saber-de-losevangelicos-le-contaron-mal/, consultado el 13 de mayo de 2020. 
Vaggione, Juan Marcos (2005). "Reactive Politicization and Religious Dissidence. The Political Mutations of the Religious in Social Theory and Practice", Social Theory and Practice, vol. 31, núm. 2, pp. 233-255. https://doi.org/10.5840/soctheorpract200531210

Wynarczyk, Hilario (2009). Ciudadanos de dos mundos. El movimiento evangélico en la vida pública argentina 1980-2001. Buenos Aires: unsam Edita. (2010). Saly luz a las naciones. Evangélicos y política en la Argentina (19802001). Buenos Aires: Instituto Di Tella / Siglo XxI.

(2014). Tres evangelistas carismáticos: Omar Cabrera, Héctor Aníbal Giménez y Carlos Annacondia. Buenos Aires: Diversa.

(2018). "Argentina: ¿Vino nuevo en odres viejos? Evangélicos y política", en José Luis Pérez Guadalupe y Sebastian Grundberger (ed.). Evangélicos y poder en América Latina. Lima: Konrad Adenauer Stiftung / Instituto de Estudios Social Cristianos, pp. 107-140.

Nicolás Panotto es licenciado en Teología (IU ISEDET), magister en Antropología Social y Política y doctor en Ciencias Sociales (FLAcso Argentina). Investigador asociado del Instituto de Estudios Internacionales (INTE) de la Universidad Arturo Prat, Chile. Director del Grupo de Estudios Multidisciplinarios sobre Religión e Incidencia Pública (GEMRIP). Especialista en las áreas de religión y política, campo evangélico latinoamericano y teología pública. Autor de $\mathrm{Fe}$ que se hace pública (2019), Descolonizar el saber teológico latinoamericano (2018), Religiones, política y Estado laico en América Latina (2017), Religión, política y poscolonialidad en América Latina (2016), entre otros. ORCID: 0000-0002-0513-7175 
Ángela Renée de la Torre Castellanos

Directora de Encartes

Arthur Temporal Ventura

Editor

Verónica Segovia González

Diseño y formación

Cecilia Palomar Verea

María Palomar Verea

Corrección

Saúl Justino Prieto Mendoza

Difusión

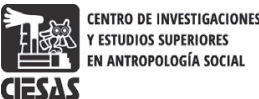

ClESAS
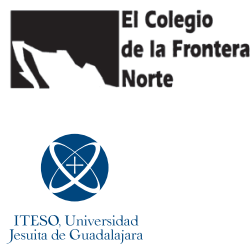

Equipo de coordinación editorial

Renée de la Torre Castellanos Directora de Encartes - Rodrigo de la Mora Pérez Arce ITeso - Arcelia Paz ciesas-Occidente - Santiago Bastos Amigo ciesas-Occidente Manuela Camus Bergareche Universidad de Guadalajara - Olivia Teresa Ruiz Marrujo El cOLEF - Christian Omar Grimaldo Rodríguez ITESO

\section{Comité editorial}

América Molina del Villar Directora general de ciesAS - Alberto Hernández Hernández Presidente de El cOLEF Enrique Páez Agraz Director del Departamento de Estudios Socioculturales del iтeso - Julia Esther Preciado Zamora CiESAS-Occidente - Subdirección difusión y publicaciones de CIESAS - Érika Moreno Páez Coordinadora del departamento de publicaciones de El colef - Manuel Verduzco Espinoza Director de la Oficina de Publicaciones del iteso - José Manuel Valenzuela Arce El colef • Luz María Mohar Betancourt Ciesas-Ciudad de México - Ricardo Pérez Monfort cIEsas-Ciudad de México • Sévérine Durin Popy CIESAS-Noreste • Carlos Yuri Flores Arenales Universidad Autónoma del Estado de Morelos • Sarah Corona Berkin DEcs/Universidad de Guadalajara - Norma Iglesias Prieto San Diego State University - Camilo Contreras Delgado El coleF • Alejandra Navarro Smith ITESO

Cuerpo académico asesor

Alejandro Frigerio

Universidad Católica

Argentina-Buenos Aires

Alejandro Grimson

usam-Buenos Aires

Alexandrine Boudreault-Fournier

University of Victoria-Victoria

Carlo A. Cubero

Tallinn University-Tallin

Carlo Fausto

UFrJ-Rio de Janeiro

Carmen Guarini

uBA-Buenos Aires

Caroline Perré

Centro de Estudios Mexicanos y

Centroamericanos-Ciudad de

México

Clarice Ehlers Peixoto

UERJ-Rio de Janeiro

\section{Claudio Lomnitz}

Columbia-Nueva York

Cornelia Eckert

UFrgs-Porto Alegre

Cristina Puga

unam-Ciudad de México

Elisenda Ardèvol

Universidad Abierta de

Cataluña-Barcelona

Gastón Carreño

Universidad de

Chile-Santiago

Gisela Canepá

Pontificia Universidad

Católica del Perú- Lima

Hugo José Suárez

unam-Ciudad de México

Jesús Martín Barbero

Universidad Javeriana-Bogotá
Julia Tuñón

INAH-Ciudad de México

María de Lourdes Beldi

de Alcantara

UsP-Sao Paulo

Mary Louise Pratt

NYU-Nueva York

Pablo Federico Semán

CONICET/UnSAM-Buenos Aires

Renato Rosaldo

NYU-Nueva York

Rose Satiko Gitirana Hikji

UsP-Sao Paulo

Rossana Reguillo Cruz

ITESO-Guadalajara

Sarah Pink

RMIT-Melbourne

Encartes, año 3, núm 6, septiembre 2020-febrero 2021, es una revista académica digital de acceso libre y publicación semestral editada por el Centro de Investigaciones y Estudios Superiores en Antropología Social, calle Juárez, núm. 87, Col. Tlalpan, C. P. 14000, México, D. F., Apdo. Postal 22-048, Tel. 548735 70, Fax 565555 76, encartesantropologicos@ciesas.edu.mx. Directora de la revista: Ángela Renée de la Torre Castellanos. Alojada en la dirección electrónica http://www.encartesantropologicos.mx. ISSN: 2594-2999. Las opiniones expresadas por los autores no necesariamente reflejan la postura de la revista. Se autoriza la reproducción parcial de los materiales publicados siempre y cuando se haga con fines estrictamente no comerciales y se cite la fuente. Salvo excepciones explicitadas, todo el contenido de la publicación está bajo una Licencia Creative Commons Atribución-NoComercial 4.0 Internacional. 